\title{
Incidence of registered visual impairment in the Nordic child population
}

National Eye Clinic for the Visually Impaired, Copenhagen, Denmark T Rosenberg

The Norwegian Registry of Blindness, The National Hospital, University of Oslo, Norway

T Flage

E Hansen

The County Medical Officer, Hedmark, Norway

R Riise

The Finnish Register of the Visually

Handicapped, Finnish

National Agency for

Welfare and Health,

Helsinki, Finland

S-L Rudanko

The Icelandic Low

Vision Clinic,

Reykjavik, Iceland

$G$ Viggosson

Department of

Ophthalmology,

University of Lund,

Sweden

K Tornqvist

Correspondence to:

Thomas Rosenberg, $M D$

1 Rymarksvej, DK-2900

Hellerup, Denmark.

Accepted for publication

13 September 1995

Thomas Rosenberg, Tor Flage, Egill Hansen, Ruth Riise, Sirkka-Liisa Rudanko, Gudmundur Viggosson, Kristina Tornqvist

\section{Abstract}

A collaborative, population based, prospective register study on the incidence of visual impairment in children during the year 1993 was carried out in five Nordic countries with a total population of 17 million inhabitants. The child population was 3.8 million individuals aged 0-17 years. The following variables were taken into account: nationality, age, sex, diagnoses, aetiology, degree of visual impairment, and additional impairments. Classification routines from an earlier prevalence study were used. The present study included 304 children corresponding to an incidence of notification of $8 / 100000$ children, varying from $5 \cdot 7$ to $11 \cdot 1$ in the five countries. Fifty per cent of the visually impaired children were reported before they were 3 years of age. In approximately $45 \%$ of the children, visual impairment was due to various brain disorders, with cerebral amblyopia and secondary optic atrophy as the two leading causes. The relative impact of retinopathy of prematurity had decreased from the third most frequent cause $(10 \%)$ in the prevalence study to seventh place $(4 \%)$ in the incidence study. Two thirds of the children had additional impairments and these children also suffered from the most severe visual impairments. Among aetiological factors the majority $(64 \%)$ were prenatal. The overall male:female ratio of $1.4: 1$ was identical to the sex ratio of the prevalence study.

(Br F Ophthalmol 1996; 80: 49-53)

In an earlier investigation the prevalence of visual impairment in Nordic children was studied, based on a retrospective analysis of data from four national blind registers. ${ }^{1}$ The study material was collected by continuous registration over a 17 year period.

The present study was initiated to elucidate the current situation with regard to low vision and blindness in children.

The study design was a multinational, population based, prospective incidence study based on standardised registered data.

\section{Study population and methods}

Five Nordic countries participated in the project, representing a population of $17 \cdot 1$ million on 1 January 1994 according to national statistical surveys. The corresponding background child population aged $0-17$ years was 3818001 .
The investigation was based on reports received by the national registers for the blind during the year 1993; the registers in Denmark, Iceland, Finland, and Norway have been described in an earlier prevalence study. ${ }^{1}$ The present investigation also included the seven southernmost counties in Sweden where a register for visually impaired children was established in $1990 .^{2}$ The Danish and Swedish registers are dedicated child registers while the remaining national blind registers comprise all age groups. All registers are strictly population based. Despite identical classification routines the prevalence study demonstrated significant differences among the Nordic countries, as prevalence rates (all visual impairment categories) varied between $48 / 100000$ and $105 / 100000$. The corresponding blindness rates varied between $15 / 100000$ and $41 / 100000$. These differences were mainly ascribed to underregistration in the countries with the lowest rates.

A child with a measured or supposed visual acuity below $6 / 18$ or an equivalent visual field defect was included in the study. Severe ocular motor impairment such as, for example, congenital motor apraxia, was also included owing to the ensuing visual disability.

A protocol was worked out based on a diagnostic coding system developed during the preceding prevalence study. The coding system included modified WHO ICD9 ophthalmic and systemic diagnoses, aetiologies, and a grading of visual impairment categories according to the World Health Organisation. ${ }^{34}$ Diagnostic definitions and classification procedures were harmonised and exemplified.

A common report form for the five participating countries was prepared, comprising 15 variables. Registration was carried out with anonymised patient data, and the study was approved by the respective national data security agencies.

To ensure uniformity in the handling of the case reports each form was evaluated individually by all authors in the project. Inconsistencies were discussed and corrected according to common guidelines during joint meetings.

\section{Results}

INCIDENCE AND AGE DISTRIBUTION

The material comprised 304 reports, corresponding to an incidence of notification ( $\mathrm{I}_{N}=$ number of visually impaired reported per 100000 children aged 0-17 years per year) of 
Table 1 Number of registered children by nationality, background population 0-17 years, and national incidences

\begin{tabular}{lccrrrr}
\hline & Denmark & Finland & Iceland & Norway & \multicolumn{2}{c}{ Southern Sweden Total } \\
\hline Total population & 5196642 & 5077912 & 264922 & 4324815 & 2242876 & 17107167 \\
Child population & 1082877 & 1168519 & 73459 & 995723 & 497423 & 3818001 \\
Reported number of visually impaired in 1993 & 112 & 67 & 8 & 62 & 55 & 304 \\
$\mathrm{I}_{N}$ (cerebral amblyopia excluded) & $10 \cdot 3$ & $5 \cdot 7$ & $10 \cdot 9$ & $6 \cdot 2$ & $11 \cdot 1$ & $8 \cdot 0$ \\
$\mathrm{I}_{N}$ (1) & $7 \cdot 5$ & $5 \cdot 1$ & $8 \cdot 2$ & $5 \cdot 2$ & $7 \cdot 0$ & $6 \cdot 1$ \\
\hline
\end{tabular}

$\mathrm{I}_{N}=$ Incidence of notification=number of reported visually impaired per 100000 children per year aged 0-17 years.

$8 / 100000$. The national incidences are shown in Table 1 .

Figure 1 shows the cumulative age distribution from the four largest populations. Nearly $50 \%$ of the registered children were less then 3 years old at registration, indicating a relatively high efficiency in the identification of congenital and neonatal visual impairment. In Iceland, six of the eight reported children were born in 1991-3.

\section{CAUSES OF BLINDNESS}

\section{Diagnoses}

Among the 304 cases, 51 ophthalmic diagnoses were encountered as the main blinding condition. These diagnoses could be divided into two nosological main groups, a 'brain' group and an 'ocular' group, according to the primary site of the lesion. The ocular group was subdivided into three groups: congenital anomalies, dystrophies, and miscellaneous (Table 2).

In the 'brain' group, including visual impairment secondary to brain disorders (142 cases), the two dominant diagnoses were cerebral amblyopia (70 cases) and secondary optic atrophy (57 cases).

A separate analysis of the 70 cases with cerebral amblyopia demonstrated a multitude of aetiologies. Thirty cases were prenatal, among which 15 were unspecified. Nine out of 12 genetic cases were due to chromosomal rearrangements. In 21 cases perinatal aetiologies were identified, eight of which involved prematurity. Eleven cases had infantile or juvenile aetiology, and in eight cases the aetiology was unknown. The sex distribution was 39 males and 31 females. An even distribution

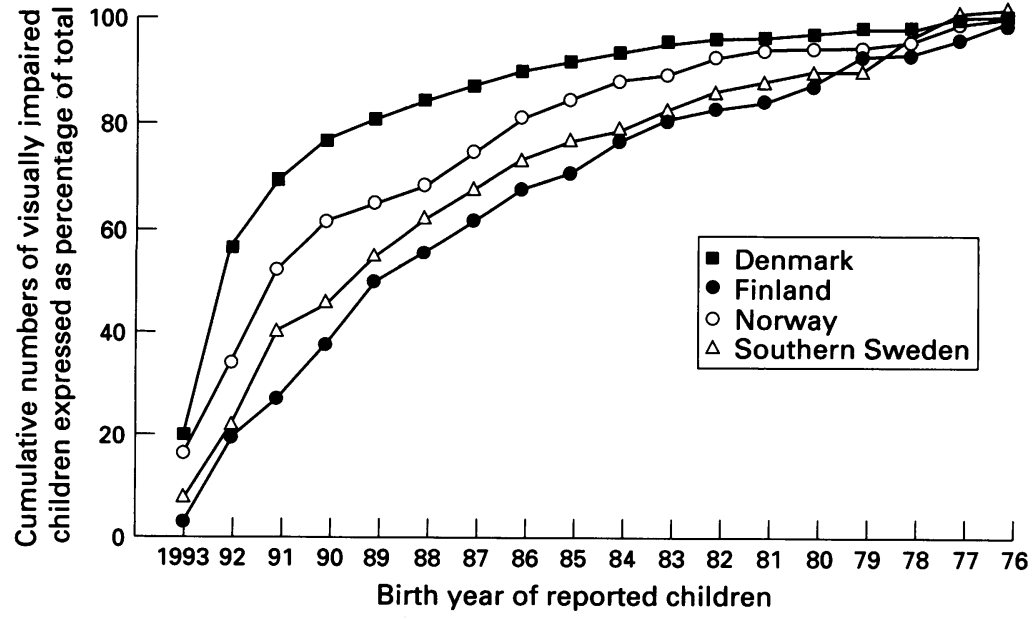

Figure 1 Age distribution among visually impaired children reported during 1993 from four Nordic countries. among the WHO categories of visual impairment was noted: 15 cases in category 1,12 cases in category 2, 19 cases in category 3,17 cases in category 4 , and seven cases in category 9.

Within the 'ocular' group the largest subgroup ( 82 cases, $49 \%$ ) was made up of congenital anomalies with congenital nystagmus (27 cases, 16\%), congenital cataract (19 cases, $11 \%$ ), optic nerve hypoplasia (15 cases, $9 \%$ ), albinism (nine cases, $5 \%$ ), and congenital dislocation of the lens (eight cases, 5\%). When specified diagnostic entities were grouped under their common headings, $80 \%$ of the cases had one out of seven diagnoses represented by more than 10 cases (Table 3).

\section{Aetiologies}

Table 4 shows the distribution of the material with respect to aetiology. The majority $(64 \%)$ were prenatal and dominated by two groups of equal size; 99 genetic cases and 99 cases with unknown aetiology. Significant perinatal aetiological factors were encountered in 63 children (21\%) and only $28(9 \%)$ had a visual impairment with postnatal aetiology. In 18 children $(6 \%)$ the aetiology was coded as unknown both with respect to specific factors as well as the time of interference.

SEX

The sex distribution is shown in Table 4. The overall sex ratio among 304 children was 176 males and 128 females (sex ratio $M: F=1 \cdot 4: 1$ ). As expected, genetic aetiology accounted for part of the male dominance, but also prenatal unknown aetiology shows conspicuous male overrepresentation (sex ratio 1.4:1). Chromosomal aetiology demonstrated the opposite tendency. Among perinatal aetiologies the number of males were twice the number of females.

\section{IMPAIRMENTS}

Table 5 demonstrates the correlation between visual impairment and the different combinations of hearing, motor, and mental disabilities. In 92 children $(30 \%)$ the visual impairment was the only impairment reported. Among these children, $56(61 \%)$ belonged to WHO category 1 and thus had only a moderate visual impairment, representing $47 \%$ of the group with the best visual acuity. This is in contrast with 15 children $(16 \%)$ of the 95 with mental and motor impairment who belonged to WHO category 1 . Among eight deaf-blind children, one had Usher syndrome, while the 
Table 2 Three hundred and four cases distributed according to four nosological groups, principal ophthalmic diagnoses, and nationality

\begin{tabular}{|c|c|c|c|c|c|c|}
\hline & Denmark & Finland & Iceland & Norway & Sweden & Total \\
\hline Sequelae to brain disorders: & & & & & & 135 \\
\hline Cerebral amblyopia & 31 & 7 & 2 & 10 & 20 & 70 \\
\hline Secondary optic atrophy & 23 & 25 & 2 & 3 & 4 & 57 \\
\hline Hemianopia & 0 & 0 & 0 & 2 & 2 & 4 \\
\hline Congenital nystagmus (secondary) & 2 & 1 & 0 & 0 & 1 & 4 \\
\hline \multicolumn{6}{|l|}{ Congenital ocular anomalies: } & 106 \\
\hline Congenital nystagmus (unspecified) & 16 & 3 & 0 & 1 & 3 & 23 \\
\hline Optic nerve hypoplasia & 4 & 3 & 0 & 4 & 4 & 15 \\
\hline Congenital cataract (unspecified) & 5 & 1 & 1 & 2 & 1 & 10 \\
\hline Congenital ectopia of the lens & 2 & 0 & 0 & 4 & 2 & 8 \\
\hline Congenital cataract (hereditary) & 5 & 1 & 0 & 1 & 0 & 7 \\
\hline Chorioretinal scar & 1 & 1 & 0 & 2 & 1 & 5 \\
\hline Congenital nystagmus (hereditary) & 0 & 1 & 0 & 1 & 2 & 4 \\
\hline Microphthalmos & 1 & 1 & 0 & 1 & 1 & 4 \\
\hline Oculocutaneous albinism & 0 & 0 & 0 & 4 & 0 & 4 \\
\hline Ocular albinism & 1 & 2 & 0 & 1 & 0 & 4 \\
\hline Anterior chamber dysgenesis & 0 & 2 & 0 & 1 & 0 & 3 \\
\hline Infantile cataract & 0 & 1 & 0 & 1 & 0 & 2 \\
\hline Anophthalmos (congenital) & 0 & 2 & 0 & 0 & 0 & 2 \\
\hline Aniridia & 0 & 1 & 0 & 0 & 1 & 2 \\
\hline Retinal dysplasia & 0 & 1 & 0 & 1 & 0 & 2 \\
\hline Coloboma of choroid and retina & 0 & 1 & 0 & 1 & 0 & 2 \\
\hline Falciform retinal fold & 1 & 0 & 0 & 1 & 0 & 2 \\
\hline Infantile glaucoma & 0 & 0 & 0 & 0 & 1 & 1 \\
\hline Achromatopsia & 0 & 0 & 0 & 0 & 1 & 1 \\
\hline Congenital stationary nightblindness & 1 & 0 & 0 & 0 & 0 & 1 \\
\hline Congenital glaucoma & 1 & 0 & 0 & 0 & 0 & 1 \\
\hline Congenital cataract with microcornea & 0 & 0 & 0 & 1 & 0 & 1 \\
\hline Coloboma of iris & 1 & 0 & 0 & 0 & 0 & 1 \\
\hline Congenital ptosis & 1 & 0 & 0 & 0 & 0 & 1 \\
\hline Albinism (unspecified) & 0 & 0 & 0 & 0 & 1 & 1 \\
\hline \multicolumn{6}{|l|}{ Ocular dystrophies: } & 32 \\
\hline Leber congenital amaurosis & 2 & 1 & 0 & 2 & 1 & 6 \\
\hline \multicolumn{7}{|l|}{ Pigmentary retinal dystrophy } \\
\hline (unspecified) & 1 & 0 & 0 & 2 & 1 & 4 \\
\hline Retinitis pigmentosa & 0 & 2 & 0 & 2 & 0 & 4 \\
\hline Retinal dystrophy (metabolic) & 0 & 1 & 1 & 0 & 1 & 3 \\
\hline $\mathrm{X}$ linked juvenile retinoschisis & 0 & 0 & 0 & 1 & 1 & 2 \\
\hline Cone dystrophy & 0 & 1 & 0 & 1 & 0 & 2 \\
\hline Retinal dystrophy (Stargardt) & 2 & 0 & 0 & 0 & 0 & 2 \\
\hline Optic atrophy (hereditary, AD) & 1 & 1 & 0 & 0 & 0 & 2 \\
\hline Usher syndrome & 0 & 0 & 0 & 0 & 1 & 1 \\
\hline Familial exudative vitreoretinopathy & 0 & 0 & 0 & 1 & 0 & 1 \\
\hline Vitreoretinal dystrophy (unspecified) & 0 & 0 & 0 & 1 & 0 & 1 \\
\hline Gyrate dystrophy of choroid and retina & 0 & 1 & 0 & 0 & 0 & 1 \\
\hline Corneal dystrophy (hereditary) & 0 & 0 & 0 & 0 & 1 & 1 \\
\hline Corneal dystrophy (metabolic) & 0 & 0 & 0 & 1 & 0 & 1 \\
\hline Optic atrophy (hereditary, unspecified) & 0 & 1 & 0 & 0 & 0 & 1 \\
\hline \multicolumn{7}{|l|}{ Miscellaneous: } \\
\hline Retinopathy of prematurity (cicatricial) & 7 & 3 & 0 & 3 & 0 & 13 \\
\hline High myopia & 1 & 1 & 0 & 0 & 3 & 5 \\
\hline Amblyopia (unspecified) & 1 & 0 & 0 & 1 & 1 & 3 \\
\hline Retinoblastoma & 0 & 0 & 0 & 2 & 0 & 2 \\
\hline Optic neuritis (unspecified) & 0 & 0 & 0 & $\overline{1}$ & 0 & 1 \\
\hline Optic atrophy (unspecified) & 1 & 1 & 2 & 1 & 0 & 5 \\
\hline Congenital ocular motor apraxia & 0 & 0 & 0 & 1 & 0 & 1 \\
\hline Total & 112 & 67 & 8 & 62 & 55 & 304 \\
\hline
\end{tabular}

remaining seven had either cerebral amblyopia (four cases) or secondary optic atrophy (three cases).

\section{Discussion}

The epidemiology of severe visual impairment in children is attracting considerable attention owing to its significant psychological, educational, and socioeconomic consequences. ${ }^{56}$ Besides reflecting the living conditions and morbidity of a population in a broad sense, the prevalence and pattern of visual impairment in

Table 3 The relative frequency of the seven most common conditions responsible for visual impairment in Nordic children

\begin{tabular}{llll}
\hline & $\begin{array}{l}\text { Incidence study } \\
1993^{\star}(n=304)\end{array}$ & $\begin{array}{c}\text { Prevalence study } \\
1990+(n=2527)\end{array}$ & $\begin{array}{c}\text { Incidence study } \\
1985 \ddagger(n=150)\end{array}$ \\
\hline Cerebral amblyopia & $70(23 \%)$ & $276(11 \%)$ & $27(18 \%)$ \\
Secondary optic atrophy & $57(19 \%)$ & $483(19 \%)$ & $39(26 \%)$ \\
Congenital nystagmus & $27(9 \%)$ & $177(7 \%)$ & $11(7 \%)$ \\
Pigmentary retinal dystrophy & $19(6 \%)$ & $202(8 \%)$ & $15(10 \%)$ \\
Congenital cataract & $18(6 \%)$ & $214(8 \%)$ & $7(5 \%)$ \\
Optic nerve hypoplasia & $15(5 \%)$ & $85(3 \%)$ & - \\
Retinopathy of prematurity & $13(4 \%)$ & $247(10 \%)$ & $5(3 \%)$ \\
\hline
\end{tabular}

^Figures from the present study. + Figures from an earlier Nordsyn study. ${ }^{3}$ ‡Figures from an earlier Danish study. children might serve as a measure of quality in health care, especially with regard to the pregnancy and the neonatal period. Moreover, the analysis of visual impairment in children is an inevitable prerequisite for preventive endeavours.

On a global scale, childhood blindness is a far greater health problem in large parts of Africa, Asia, and South American than in Western Europe. ${ }^{7}$ Furthermore, figures on prevalences are only reflecting part of the problem since many blind children in developing countries have a very shortened life span. A considerable proportion of this childhood blindness is preventable.

Early visual deprivation in children, nevertheless, remains a significant health problem in modern society, in which even a moderate reduction in visual acuity may have a significant impact on social adaptation.

Recently, our group reported on the visually impaired children from four Nordic countries, based on register data from the preceding 18 year period. ${ }^{1}$ This prevalence study demonstrated substantial differences in registrational efficiency among the participating countries. These differences still exist, but a tendency to level out has been noticed. In a similar incidence study from Denmark in 1985, the incidence of notification was 14 per $100000 .^{8}$ This higher incidence is explained by the inclusion of children with a visual acuity of $6 / 18$. With the same visual inclusion criterion applied to the year 1993, the number of registered children in Denmark was 143, corresponding to an incidence of notification of 13.2 per 100000 .

The age distribution of the material shows that the majority of visual impairments are diagnosed during the first years of life (Fig 1). This may be taken as an indicator of a high efficiency in the screening and assessment of neonates and infants in the Nordic countries. Furthermore, the age distribution underlines the impact of congenital and perinatal visual impairment. This observation is corroborated by the aetiological classification, grouping $85 \%$ of the cases as prenatal or perinatal.

The distribution among pathological conditions responsible for the visual deficit underlines the trend from earlier investigations towards a growing proportion of visual impairment due to brain damage. The most impressive change is the occurrence of cerebral amblyopia, being the most frequent diagnosis with 70 out of 304 cases (Table 3).

Compared with the figures from the prevalence study, the relative frequency of cerebral amblyopia has risen from $11 \%$ to $23 \%$. Cerebral amblyopia, cerebral visual impairment, or cortical blindness is a relatively new diagnostic entity which hardly occurred in earlier statistics on childhood blindness. ${ }^{910}$ This may be explained partly by the segregation in earlier years of impairment populations into visually and mentally retarded, but also seems related to a change in the conception of visual impairment. On the other hand, a real rise in the incidence and prevalence of cerebral amblyopia has been noted also in 
Table 4 Aetiology/sex distribution among 304 visually impaired children

\begin{tabular}{lrrl}
\hline & \multicolumn{2}{l}{ Number } & \\
\cline { 2 - 3 } Aetiology & Males & Females & \multirow{2}{*}{$\begin{array}{l}\text { Sex ratio } \\
\text { M:F }\end{array}$} \\
\hline Prenatal: & 114 & 82 & $1 \cdot 4: 1$ \\
Genetic & 50 & 31 & \\
Anomalies of chromosomes & 6 & 12 & \\
Infectious diseases & 3 & 2 & \\
Other specified influence & 3 & 0 & \\
Unspecified & 52 & 37 & \\
Perinatal: & 41 & 22 & $1 \cdot 9: 1$ \\
Prematurity & 17 & 6 & \\
$\quad$ Dysoxygenation & 6 & 6 & \\
Other complications & 10 & 6 & \\
Maturity & 8 & 4 & \\
$\quad$ Dysoxygenation & 10 & 18 & $0 \cdot 6: 1$ \\
$\quad$ Other complications & 0 & 1 & \\
Infantile juvenile: & 3 & 4 & \\
Infectious eye diseases & 5 & 3 & \\
Meningitis, encephalitis & 1 & 5 & \\
Intracranial neoplasms & 1 & 5 & \\
Other CNS diseases & 11 & 6 & $1 \cdot 8: 1$ \\
Miscellaneous & 176 & 128 & $1 \cdot 4: 1$ \\
Unknown cause and time & & & \\
Total & & &
\end{tabular}

other countries. ${ }^{11} 12$ Improved medical care allows many critically ill children to survive, but often with brain damage which may involve the visual system. ${ }^{11}$ The proportion of children registered as visually impaired due to cerebral amblyopia varies among the Nordic countries, possibly because of different reporting habits among ophthalmologists. In southern Sweden, $36 \%$ of the registered cases belonged to this group, while Finland only had $10 \%$ of children with cerebral amblyopia. When cerebral amblyopia was excluded from the incidence calculations, the differences between the national figures were reduced considerably (Table 1).

The relatively large proportion of congenital anomalies is another significant feature of this material. Indeed, it should be noted that infantile and juvenile glaucoma have become rare causes of visual impairment as the result of early and successful surgical intervention. The same might be said of congenital cataracts, which, however, are still represented among the common causes of visual impairment (Table 3). This is even more surprising as maternal rubella has become nearly extinct as a consequence of vaccination programmes. Nevertheless, dense congenital cataracts are often accompanied by congenital nystagmus, which is not relieved by cataract extraction. Other reasons for low vision in aphakic children may be delayed operation and/or suboptimal optical rehabilitation with either glasses or contact lenses, as well as other subtle anomalies in eyes with cataract.

Compared with the prevalence study of 1990 , the relative frequency of retinopathy of prematurity fell from $10 \%$, ranking as the third most common diagnosis, to $4 \%$, or the seventh most common cause of visual impairment in this study (Table 3 ). This is probably a consequence of the efficient screening programmes performed today at most neonatal intensive care units.

The average male/female ratio observed in 1993 was 1.4:1 (Table 4), which was identical to the sex ratio in the prevalence study. ${ }^{13}$ The same proportion was noticed in the prenatal aetiological subgroup which was composed of genetic cases (sex ratio 1·6:1) and unspecified $(1 \cdot 4: 1)$. Interestingly, the sex ratio among children with chromosome anomalies was inverted. Even more conspicuous was the male dominance found in the subgroup with perinatal aetiology with a sex ratio of 1.9:1.

In 66 cases (22\%) no data on additional impairments were recorded. Among the remaining 238 children, only 92 cases were affected by an isolated visual impairment. This means that at least 146 cases $(61 \%)$ among the sufficiently enlightened cases had two or more types of impairment. In the Nordic prevalence study $^{1}$ the proportion of visually impaired children with additional impairments varied between $30 \%$ and $50 \%$. Thus, a trend towards an increase in multiply impaired children among the visually impaired child population is demonstrated.

\section{Conclusions}

Based on register data the incidence of visual impairment in the Nordic child population in 1993 was $8 / 100000$ children.

Fifty per cent of visually impaired children were reported before they were 3 years of age.

Brain disorders accounted for approximately $45 \%$ of cases, with cerebral amblyopia and secondary optic atrophy as the leading causes.

The relative impact of retinopathy of prematurity had decreased from the third most frequent cause $(10 \%)$ during the study period 1973-89 to seventh place (4\%) in 1993 .

The aetiology was confined to the prenatal period in two thirds of the cases.

The average male:female ratio was $1 \cdot 4: 1$. Cases with monogenic disorders had a sex ratio of $1 \cdot 6: 1$, and in cases with perinatal aetiology

Table 5 WHO visual acuity categories cross tabulated with impairment groups

\begin{tabular}{|c|c|c|c|c|c|c|c|}
\hline \multirow[b]{3}{*}{$\begin{array}{l}\text { Impairment } \\
\text { group }\end{array}$} & \multicolumn{6}{|c|}{ Visual acuity category } & \multirow[b]{3}{*}{ Sum } \\
\hline & 1 & 2 & 3 & 4 & 5 & 9 & \\
\hline & $\begin{array}{l}<6 / 18 \\
t o \\
\geqslant 6 / 60\end{array}$ & $\begin{array}{l}<6 / 60 \\
t o \\
\geqslant 3 / 60\end{array}$ & $\begin{array}{l}<3 / 60 \\
\text { to } \\
\geqslant 1 / 60\end{array}$ & $\begin{array}{l}<1 / 60 \\
\text { to } \\
\text { light perception }\end{array}$ & $\begin{array}{l}\text { No light } \\
\text { perception }\end{array}$ & Unspecified & \\
\hline $\begin{array}{l}\text { Hearing } \\
\text { Motor } \\
\text { Mental } \\
\text { Mental and hearing } \\
\text { Mental and motor } \\
\text { Mental, motor, and hearing } \\
\text { No data } \\
\text { Visual impairment only }\end{array}$ & $\begin{array}{r}1 \\
10 \\
9 \\
1 \\
15 \\
0 \\
28 \\
56\end{array}$ & $\begin{array}{r}0 \\
2 \\
4 \\
0 \\
18 \\
1 \\
17 \\
18\end{array}$ & $\begin{array}{r}0 \\
9 \\
0 \\
1 \\
31 \\
2 \\
7 \\
7\end{array}$ & $\begin{array}{r}0 \\
2 \\
3 \\
0 \\
18 \\
1 \\
8 \\
9\end{array}$ & $\begin{array}{l}0 \\
0 \\
1 \\
0 \\
2 \\
0 \\
3 \\
0\end{array}$ & $\begin{array}{r}0 \\
1 \\
2 \\
0 \\
11 \\
1 \\
3 \\
2\end{array}$ & $\begin{array}{r}1 \\
24 \\
19 \\
2 \\
95 \\
5 \\
66 \\
92\end{array}$ \\
\hline Total & 120 & 60 & 57 & 41 & 6 & 20 & 304 \\
\hline
\end{tabular}


the sex ratio was $1 \cdot 9: 1$. The opposite tendency was found in cases with chromosomal anomalies.

Two thirds of the children had additional impairments and these children also suffered from the most severe visual impairments. The proportion of children with additional impairments has increased compared with the study period 1972-89.

1 Riise R, Flage T, Hansen E, Rosenberg T, Rudanko S-L Viggosson G, et al. Visual impairment in Nordic children. I. Nordic registers and prevalence data. Acta Ophthalmol (Copenh) 1992; 70: 145-54.

2 Blohmé J, Tornqvist K. Visual impairment in Swedish children. I. Register and prevalence data. Acta Ophthalmol

Scand (in press).
3 Hansen E, Flage T, Rosenberg T, Rudanko S-L, Viggosson Hansen E, Flage T, Rosenberg T, Rudanko S-L, Viggosson
G, Riise R. Visual impairment in Nordic children. G, Riise R. Visual impairment in Nordic children.
III. Diagnoses. Acta Ophthalmol (Copenh) 1992; 70: III. Diag 604

4 Rosenberg T, Flage T, Hansen E, Rudanko S-L, Viggosson
G, Riise R. Visual impairment in Nordic children. II. Aetiological factors. Acta Ophthalmol (Copenh) 1992; 70: 597-604

5 Schappert-Kimmijser J, Hansen E, Haustrate-Gosset MF, Lindstedt E, Skydsgaard $\mathbf{H}$, Warburg $M$. Causes of severe visual impairment in children and their prevention. Doc Ophthalmol 1975; 39: 213-341.

6 Williamson WD, Desmond MM, Andrew LP, Hicks RN. Visually impaired infants in the $1980 \mathrm{~s}$. Clin Pediatr 1987; 26: $241-4$.

7 Foster A. Childhood blindness. Eye 1988; 2 (suppl): S27-36.

8 Rosenberg T. Visual impairment in Danish children 1985. Acta Ophthalmol (Copenh) 1987; 65: 110-7.

9 Lindstedt E. Severe visual impairment in Swedish children. Doc Ophthalmol 1972; 31: 173-202.

10 Hatfield EM. Blindness in infants and young children. Sight Saving Rev 1972; 42: 69-89.

11 Groenvald $M$, Jan JE, Leader P. Observations on the habilitation of children with cortical visual impairment. 7 Vis Impair Blind 1990; 84: 11-5.

12 Good WV, Jan JE, DeSa L, Barkovich J, Groenvald M, Hoyt CS. Cortical visual impairment in children. Surv Ophthalmol 1994; 38: 351-64.

13 Riise R, Flage T, Hansen E, Rosenberg T, Rudanko S-L, Viggosson G. Visual impairment in Nordic children. IV. Sex distribution. Acta Ophthalmol (Copenh) 1992; 70: 605-9. 